\title{
Effect of Bearing Capacity on Designing Foundations in Iraq Using STAAD Pro-v8i
}

\author{
Entidhar Al-Taie, Nadhir Al-Ansari, Sven Knutsson \\ Department of Civil, Environment and Natural Resources Engineering, Lulea University of Technology, \\ Lulea, Sweden \\ Email: entidhar.altaie@ltu.se, nadhir.alansari@ltu.se, Sven.Knutsson@ltu.se
}

Received 28 February 2014; revised 28 March 2014; accepted 4 April 2014

Copyright (C) 2014 by authors and Scientific Research Publishing Inc.

This work is licensed under the Creative Commons Attribution International License (CC BY). http://creativecommons.org/licenses/by/4.0/

(c) (i) Open Access

\section{Abstract}

Most of Iraqi soil is classified as Quaternary deposits, especially in the Mesopotamian plain and tributaries of the River Tigris. Soil varies from north to south of Iraq. These differences in soil affected the process to select the suitable type of foundation. This research is to study the effect of bearing capacity on shallow foundations in different regions of Iraq. Seventy nine samples were collected from 23 boreholes at three different locations (Mosul at the North, Baghdad at the middle and Basrah at the south of Iraq). The samples were collected at varying depth between 1 to 24 $\mathrm{m}$. They were subjected to the following testes: Atterberg limits, sieve and hydrometers, consolidation, direct shear, unconfined compression and the filed (SPT test). The values of the bearing capacity parameters ( $\phi$ and $c$ ) were obtained from the above tests. The results obtained were used in the application of the general equation of the bearing capacity. Then, the model of a building was designed (two floors, with mat foundation type) using STAAD Pro software. The average values of bearing capacity in each region were applied in the program (Mosul = $177 \mathrm{KPa}$, Baghdad $=$ $125 \mathrm{KPa}$ and Basrah = $84 \mathrm{KPa}$ ). In addition, the worst bearing capacity values were also used for the three regions (Mosul $=77 \mathrm{KPa}$, Baghdad $=68 \mathrm{KPa}$ and Basrah $=24 \mathrm{KPa}$ ). . The results obtained from the average and worst bearing capacity indicated that for Mosul, we could use shallow foundation (spread and mat used if there was basement) for different areas and for buildings with many stories. For Baghdad region, shallow foundation was more suitable for building not higher than five stories. Finally, for Basrah region, shallow foundations were an appropriate selection, but for most areas deep foundation was the right choice.

\section{Keywords}

Bearing Capacity, Soil, STAAD Pro., Laboratory Tests and Foundation

\section{Introduction}

It is important to have good feedback about the project site, because soil nature is heterogeneous [1]. All mate- 
rials used in building are artificial materials. They are produced according to the international standards or codes, such as steel, concrete, etc. When structural engineers start to design a structure, the properties of these materials, are well known for them from text books. For soil however, site investigations and laboratory tests are required. In addition, information about the geology of the site will help the designer. Therefore, tests and identifications for soil and rocks must be done at each new site before conducting any analysis [2]. Foundation is the most important part which connects the superstructure with ground. Foundations are divided into two categories: shallow foundations and deep foundation (Figure 1).

Spread foundations are mostly used in medium and small size structures, on moderate to good soil site conditions. Raft foundations are often used for larger structures when the soil has differential settlement problems and the foundations are to be under the ground water table. The contact pressure between the lower face of the shallow foundation and the implied soils is the bearing pressure [2]-[4]. The stress distribution that influences the stress zone under the foundation is to be considered for both shallow foundations and deep foundations. Figure 2 shows the theoretical vertical stress distribution under a square footing and pile foundation on the ground surface.

The influence depth of soil under foundation depends on its width [1]. The bearing capacity of soil for any site can be determined from the soil tests (field and laboratory tests). The laboratory tests that define the shear strength (bearing capacity parameters) are: direct shear, unconfined and Triaxial. Field tests are: Standard Penetration Test (SPT), Cone Penetration Test (CPT) and van shear [3]. An educational building was previously designed and analyzed using STAAD Pro.V8i software [5]. The building model was applied for three sites in different regions of Iraq (Mosul, Baghdad and Basrah). Due to the different geology and soil types in Iraq, the bearing capacity used in that analysis was obtained from engineering departments at the universities in those sites [5]. In this research soil samples were collected from different sites of the three regions of Iraq and analyzed. Thereafter, defining the best type of foundation for each region, the calculated bearing capacities from Mosul, Baghdad and Basrah regions were supplied to the STAAD Pro software model to find out the best suitable foundation for each site.

\section{Methodology}

\subsection{Nature of Iraqi Soil}

The Quaternary period (including Pleistocene and Holocene ages) affected the formation and nature of soil in Iraq. During this period, many processes took place that caused some erosion in the mountains and hills. Terraces have been formed along the Tigris and Euphrates Rivers and their tributaries as a result of changing climate. Rivers and wind filled up the Mesopotamian plain with fine texture sediments. Moreover, secondary gypsum crest has been formed and covered large areas of the deserts and the Mesopotamian plain. Almost all the soil of center and southern parts of Iraq became saline due to the natural conditions and the shallow level of ground water. Due to repeated flooding and irrigation practices, layers of mud accumulated on the original soil. As a result, most of the basin areas of the rivers are of silty soil [6]. Quaternary sediments are covering nearly $30 \%$ of the Iraqi surface area as it can be noticed on the geological map (Figure 3). They are important for the human activities and engineering works [6] [7].

\subsection{Study Area}

Three areas were tested. They are:

1-Mosul: This city is located north of Iraq (Figure 4). The nature of soil in Mosul region includes different types. Clayey (expansive type) covers most of the regions of Mosul city. Furthermore, alluvium sediments are usually located near the banks of Tigris River, and primary gypsum is located in west part of Mosul [9]-[13].

2-Baghdad: This city is the capital of Iraq. It is located in the central part of the country in the middle Mesopotamian plain (Figure 4). The area is covered by accumulation of the deposits brought by the two rivers (Tigris and Euphrates). The area was occupied by humans since the dawn of civilization. Early human activities affected the soil formations because they were depending mainly on agriculture, irrigation and farm practices. These activities made numerous changes in the soil characteristics from one place to another. Over the years, soil became a sequential stratum from alluvial and sand sediment [6]. The changing course of the river caused changes in the flood plain of the river and thus changing the sequences of the deposited layers. These changes gave the soil at Baghdad unexpected and misleading characteristics. Moreover, the soil is saline because of the 


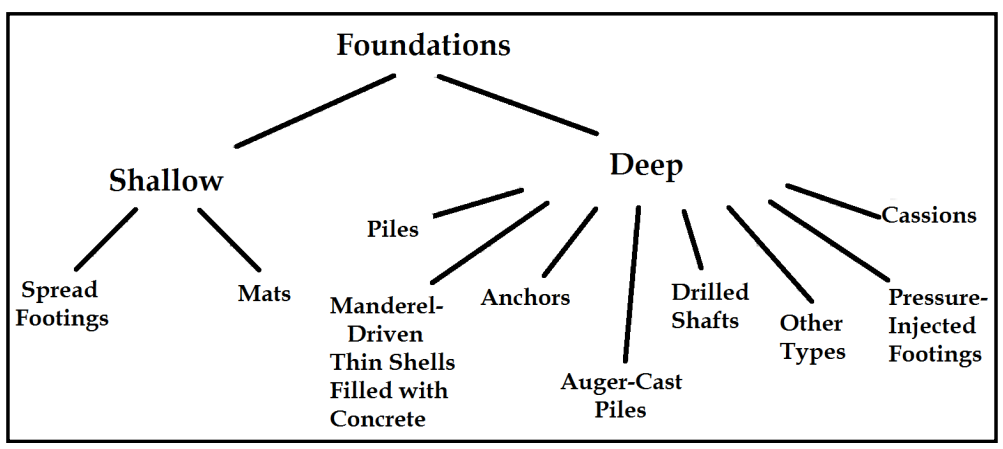

Figure 1. Classification of foundations [2].

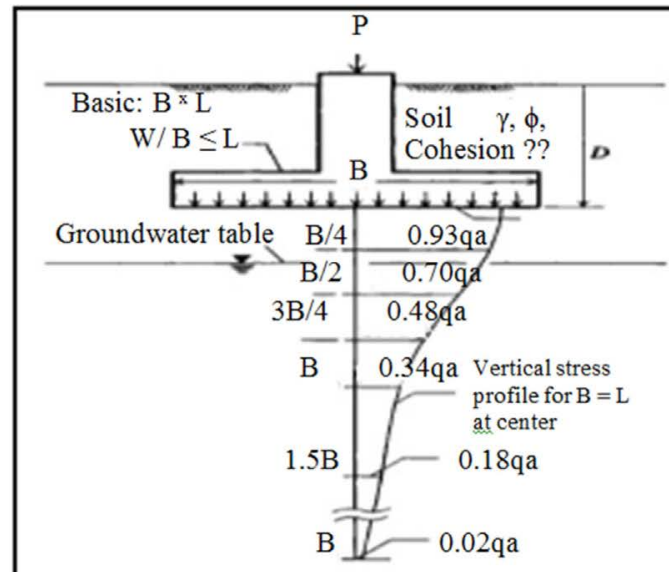

(a) Spread foundation. Base contact pressure $\mathrm{qa}=\mathrm{P} / \mathrm{BL}$ (units of $\mathrm{kPa}$, usually)

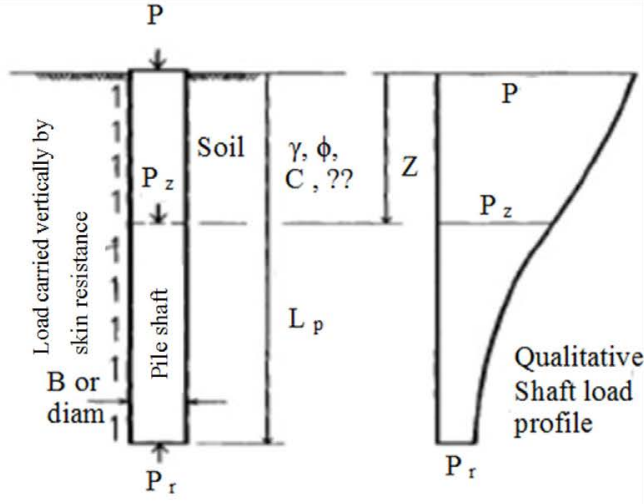

(b) Pile foundation. $\mathrm{Pp}=$ tip, point, or pile base load (units of $\mathrm{kN}$ )

Figure 2. The theoretical vertical stress distribution under a square footing and pile [1].

arid climate [6]. Based on the nature of Baghdad, soils are mostly of fluvial origin (clayey and silty) with some gypsiferous soil, and sand.

3-Basrah: Basrah region (south of Iraq) is located in the lower part of the Mesopotamian plain (Figure 4). The stratification of Basra's soil is of irregular nature and consists of different strata and lenses as a result of the depositions of the Tigris and Euphrates Rivers through geological history of the area.

Quaternary sediment consisting of lacustrine, deltaic, fluviatile and Aeolian sediment replaced each other both vertically and horizontally. In the upper part of this region, the soil consists of layers that their surfaces are naturally consolidated, which are a mixture of sediment of fluvial flood and aeolian deposits. Deep soil layer (between $20-30 \mathrm{~m}$ ) consists of very dense sand laminated with hard clay (Dibdibba deposits) representing high bearing capacity layers for heavy structures. While the upper part of Basrah area is useful for shallow foundations [14]-[16] Soil of Basrah is characterized by its fine particles fundamentally clay and silt [17].

\subsection{Data Collection}

The data were aggregated from subsurface soil investigation of 23 sites distributed all around the three regions of Iraq (Mosul, Baghdad and Basrah) as shown in Figure 4. These involve 9 boreholes drilling to depths of (3 10) meters in Mosul, 5 boreholes drilled to a depth of $(10$ - 13) meters in Baghdad and 9 boreholes drilled to depths of (10 - 24) meters in Basrah. The samples collected from ground drilling were undisturbed, disturbed and SPT.

\subsection{Laboratory Tests}

1) The collected samples were tested for the ID tests (Identification and Description of subsoil conditions) are 


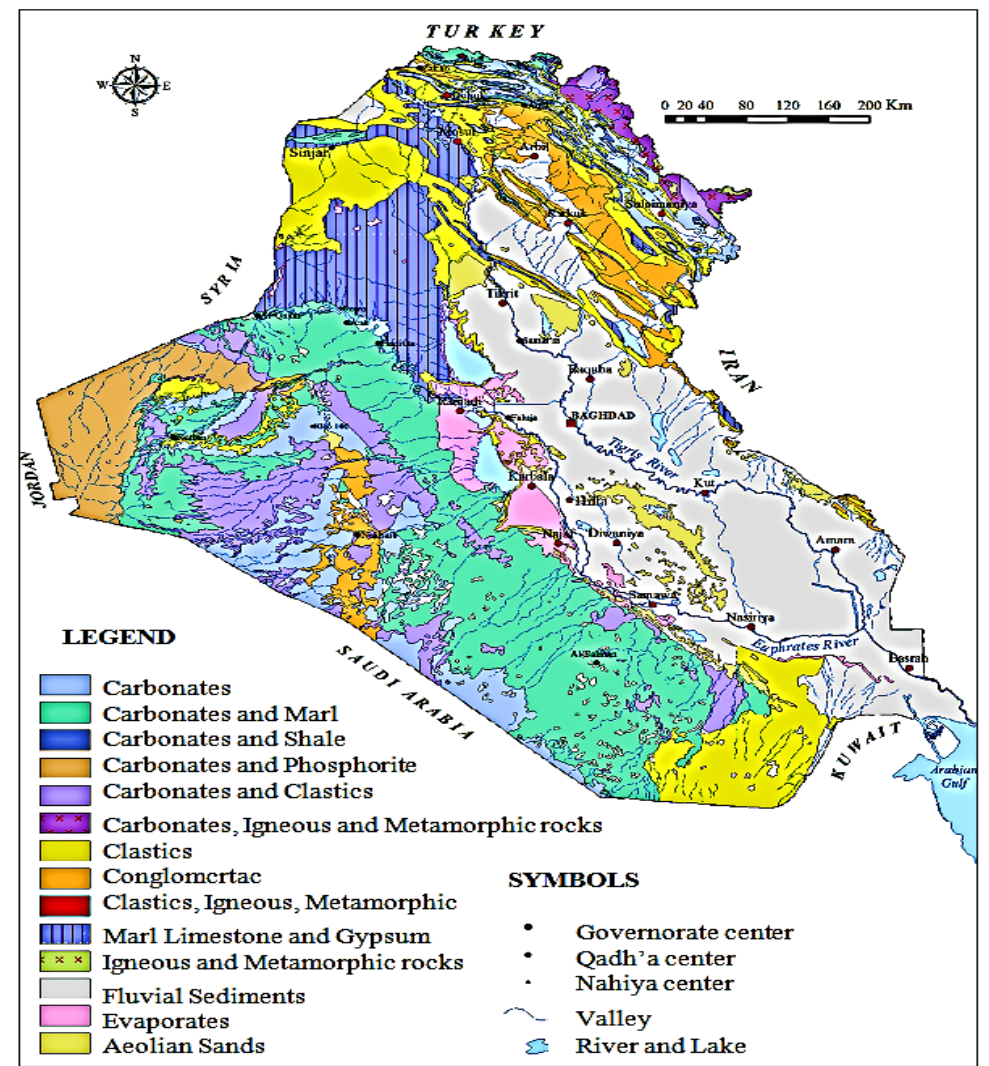

Figure 3. Geological map of Iraq [8].

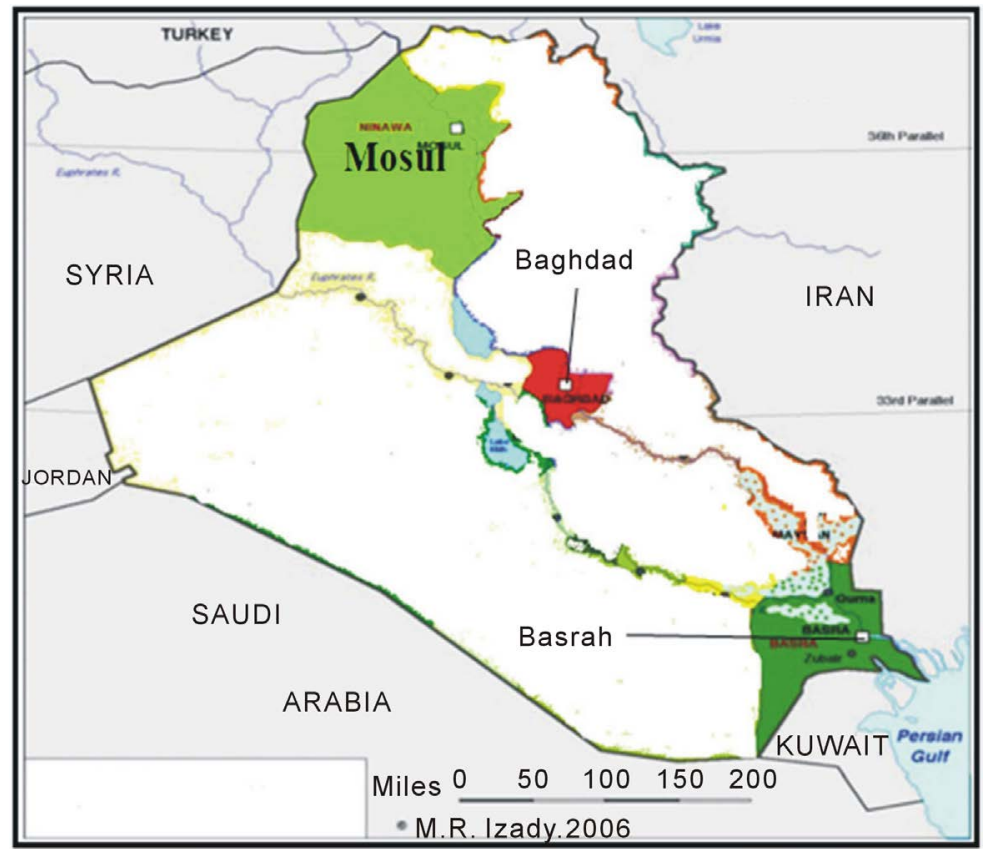

Figure 4. Locations of Mosul, Baghdad \& Basrah sites.

the Atterberg limits to obtain the liquid limit (LL), the plastic limit (PL) and the different between the LL and the PL of soil is defined as the plastic index (PI). 
To find the plastic limit, soil sample soil about 100 - 250 g passed through sieve No. 40. Water was added to the soil and mixed to the form of uniformed paste. A part of the paste was placed in casagrande cup and the surface was smoothed using spatula. After that a groove was made along the center line of soil in the cup using grooving tool. By returning the crank of the casagrande device, the two sides of the soil began to flow toward the center. The moisture sample was placed in cane and weighted. The above procedures were repeated for three to four times for each sample. Then putted the canes in the oven for 24 hours, and weighted the sample to calculate the plastic limit. This was performed according to ASTM D 4318-Standard Test Method for Liquid Limit, Plastic Limit, and Plasticity Index of Soils.

2) To classify the soil samples, sieving and hydrometer tests were performed. The sieve analysis was per-formed by using $500 \mathrm{~g}$ of each sample. The sample was sieved using sieves numbers $4,10,20,40,60,140$ and 200. Then, the stacks of sieves were placed onto shaker for 10 - 15 minutes. Then, weighted of the sample for each sieve was retained and calculations of the percent of soil size was calculated. The size distribution of the small soil fractions was performed using the hydrometer method.

3 ) To find the strength parameters angle of internal fraction $(\phi)$ and the cohesion (C) Strength tests in-cluding direct shear, and unconfined compression tests were conducted. The test was performed on three or four specimens from undisturbed soil sample. The sample was placed in a shear box. A confining stress was applied vertically to the specimen. The load applied and horizontal and vertical dial gauges attached to the shear box were measuring the displacement during the test. After that, load was applied to the top half of shear box, and readings of both gauges were recorded until the spacemen failed. Then calculations were done to obtain the values of cohesion c and angle of friction $\phi$.

4) Consolidation test was performed to obtain the three important parameters required for calculating the settlement. They are the compression index (Cc), the swelling index (Cs) and preconsolidation p Undisturbed sample used in this test. Soil specimens were trimmed in a dimension suitable to the consolidation ring using saw wire. Then, porous stone was put on the base of consolidometer under the soil specimen and on the top of it. Water was added to the consolidometer to keep the soil saturated and placed in the loading device. The loads applied to the specimen. Reading were taking for the added loads (1/4, 1/2, 1, 2, 4, 8, $16 \mathrm{Kg})$. Finally, eo, cs, pc, and cc were calculated pressure $(\mathrm{Pc})$.

5) All the above tests were performed according to the procedures given by ASTM, AASHTO and BS.

\subsection{Calculations}

The calculation had been done to find the ultimate bearing capacity following the Hansen (general) Equations (1) and (2):

$$
q_{u l t}=c N_{c} s_{c} d_{c} i_{c} g_{c} b_{c}+q N q s q d q i q g q b q+0.5 \gamma B N \gamma s \gamma d \gamma i \gamma g \gamma b \gamma
$$

where:

$q_{u l t}=$ the ultimate bearing capacity

$c=$ the cohesion of soil

$q=$ the effective stress at the level of the bottom of foundation

$\gamma=$ the unit weight of soil

$B=$ the foundation width

$N_{c}, N_{q}, N_{\gamma}=$ bearing capacity factors

$s_{c}, s_{q}, s_{\gamma}=$ shape factors

$d_{c}, d_{q}, d_{\gamma}=$ depth factors

$i_{c}, i_{q}, i_{\gamma}=$ load inclination factors

$g_{c}, g_{q}, g_{\gamma}=$ ground inclination factors

$b_{c}, b_{q}, b_{\gamma}=$ base inclination factors

$N_{c}, N_{q}, N_{\gamma}$ the values of these factors were taken from especial tables. The other factors were calculated using the following equations [3]:

Shape factors:

$\mathrm{k}=\mathrm{D} / \mathrm{B}$ for $\mathrm{D} / \mathrm{B} \leq 1$

$\mathrm{S}_{\mathrm{c}}=1.0+\mathrm{Nq}$. B/Nc. L

$\mathrm{s}_{\mathrm{q}}=1.0+\mathrm{B} / \mathrm{L} \sin \phi \ldots \ldots \ldots \ldots$ for all $\phi$

$\mathrm{s} \gamma=1.0-0.4 \mathrm{~B} / \mathrm{L}, \ldots \ldots \ldots . \mathrm{B} / \mathrm{L} \geq 0.6$ 
Depth factors:

$\mathrm{d}_{\mathrm{c}}=1.0+0.4 \mathrm{k}$

$\mathrm{d}_{\mathrm{q}}=1.0+2 \tan \phi(1-\sin \phi) 2 \mathrm{k}$

$\mathrm{d} \gamma=1.0$

Moreover, in some locations; the bearing capacity was calculated from unconfined compression test. This test can be used to obtain (cu) values, depending on the measurement of unconfined compression strength (qu). Thus, [18]:

$$
C_{u}=1 / 2 q_{u}
$$

where:

$\mathrm{Cu}=$ cohesion strength; qu = unconfined compression

Furthermore, the bearing capacity of soil for few sites was determined using the standard penetration test (SPT). The method used to define empirical values for relative density (Dr), unit weight $\left(\gamma_{\text {wet }}\right)$, angle of internal friction $(\phi)$ and undrained compressive strength $\left(q_{u}\right)$ as shown in Table 1 \& Table 2, [19].

\subsection{Results}

The results of the laboratory tests, including Atterberg limits, direct shear, unconfined and consolidation tests are given in Table 3. The tests were done for different sites in Mosul, Baghdad and Basrah. The purpose was to identify soil properties and described the soil types. Then from these values could obtain the strength of soils. Later, used these results to calculate the value of bearing capacity. In Table 4, the calculations performed for the average and worst bearing capacity for each site are tabulated.

\subsection{Model of the Study}

Modeling is a method that was used during the last 40 years by designers, architects and engineers. Many programs and softwares had been available and were used by structural and foundation engineers in design and analysis. STAAD Pro.v8i program is one of these softwares and was chosen to be used in this research for the design and analysis of the building model.

The program is computer software for structure and foundation design and analysis developed originally by international research engineers in Yorba Linda, CA. It was firstly, used for educational purposes for civil and structural engineers by Iowa state university. Then, Bently system adopted the program and developed to be used in the analysis and design for different constructions work such as structural, foundations, bridges, dams, etc., [20]. STAAD Pro program is the most popular designing software used because of its easy interface use, offering finite element, nature versatile at solve any type of problem, and collecting different codes [21].

The general procedures for the design and analysis in STAAD Pro as follow [22]:

- Drawing the geometry of the model.

- Adding the properties for beams, columns, slabs and foundations.

- Specifying the materials.

- Adding the loads (dead, live and combination).

- Analyzing the model.

Results obtained from the program are of different types, depending on the aim of the analysis. In this research, the analysis requires the base pressure of the building on the soil beneath it. Wherefore, the results were presented inform of contour. The colors of the contours reflect the value of the distribution of the bearing pressure under the foundation. The violet, pink, blue and green colors indicating that the bearing pressure is low to medium. Yellow and red colors indicating that the bearing pressure is high or exceeds the limit value.

The model used for this study was a building with two stories (ground \& 1st flower). Mat foundation was suggested for the building with dimensions of $25 \times 60$ meters. The method of design and analysis of the building model was performed using STAAD Pro.v8i Program. The dead and the live loads values used in the design were $53.5 \mathrm{KN} / \mathrm{m}^{2}$ and $8 \mathrm{KN} / \mathrm{m}^{2}$ respectively for Mosul, Baghdad and Basrah. While, the outcomes from the calculations which depend on the field and laboratory tests were used to obtain the value of the bearing capacity. The value of a safety factor used was 3; design was according to ACI code [23]. The results of the design of a building model in STAAD Pro, Program and analysis are shown in Figures 5-10.

Figure 5 and Figure 6 show the effect of the bearing pressure on the soil that supports the foundation of the 
Table 1. Consistency of clay and SPT number [3].

\begin{tabular}{ccc}
\hline Standard penetration number, $\mathbf{N}_{\mathbf{6 0}}$ & Consistency & Unconfined compression strength, $\boldsymbol{q}_{\boldsymbol{u}}\left(\mathbf{K N} / \mathbf{m}^{2}\right)$ \\
\hline $0-2$ & Very soft & $0-25$ \\
$2-5$ & Soft & $25-50$ \\
$5-10$ & Medium stiff & $50-100$ \\
$10-20$ & Stiff & $100-200$ \\
$20-30$ & Very Stiff & $200-400$ \\
$>30$ & Hard & $>400$ \\
\hline
\end{tabular}

Table 2. Empirical values for Dr, $\phi \& \gamma_{\text {wet }}$ of granular soils based on SPT at $6 \mathrm{~m}$ depth \& normally consolidated [1].

\begin{tabular}{cccccc}
\hline Description & Very loose & Loose & Medium & Dense & Very dense \\
\hline Relative density $\mathrm{D}_{\mathrm{r}}$ & 0 & 0.15 & 0.35 & 0.65 & 0.85 \\
SPT N' Fine & $1-2$ & $3-6$ & $7-15$ & $16-30$ & $?$ \\
Medium & $2-3$ & $4-7$ & $8-20$ & $21-40$ & $>40$ \\
coarse & $3-6$ & $5-9$ & $10-25$ & $26-45$ & $>45$ \\
Ф Fine & $26-28$ & $28-30$ & $30-34$ & $33-38$ & $<50$ \\
Medium & $27-28$ & $30-32$ & $32-36$ & $36-42$ & \\
coarse & $28-30$ & $30-34$ & $33-40$ & $40-50$ & $17-22$ \\
$\gamma_{\text {wet, }} \mathrm{KN} / \mathrm{m}^{3}$ & $11-16^{*}$ & $14-18$ & $17-20$ & & $20-23$ \\
\hline
\end{tabular}

Table 3. Results from laboratory tests.

\begin{tabular}{cccc}
\hline Parameters obtained from tests & \multicolumn{3}{c}{ Location } \\
\cline { 2 - 3 } & Mosul & Baghdad & Basrah \\
\hline Liquid limit (L.L) \% & $43-54$ & $34-53$ & $37-45.6$ \\
Plastic limit (P.L) \% & $22-26$ & $19-30$ & $21.33-31.9$ \\
Plastic index (P.I) \% & $17-30$ & $15-29$ & $11-18$ \\
Unit weight $(\gamma) \mathrm{KN} / \mathrm{m}^{3}$ & $15.7-19.7$ & $14.4-20.31$ & $15.1-20.1$ \\
Cohesion (C) KPa & $0-40$ & - & $0-4$ \\
Angle of internal friction $(\phi)^{\circ}$ & $15-28$ & - & $33-31$ \\
Initial void ratio $\left(e_{o}\right)$ & $0.558-0.767$ & $0.647-0.769$ & $0.72-0.90$ \\
Compression index $\left(C_{c}\right)$ & $0.065-0.28$ & $0.156-0.22$ & $0.186-0.267$ \\
Swelling index (C, $)$ & $0.011-0.156$ & $0.010-0.054$ & $0.028-0.090$ \\
Preconsolidation pressure $\left(P_{c}\right) \mathrm{KPa}$ & $70-150$ & $95-165$ & $90-135$ \\
Unconfined compression strength $\left(q_{u}\right) \mathrm{KPa}$ & - & $76-370.6$ & $24-125.1$ \\
\hline
\end{tabular}

Table 4. Results of calculated bearing capacity values.

\begin{tabular}{cccc}
\hline \multirow{2}{*}{ Locations } & \multicolumn{2}{c}{ Capacity values (KPa) } & Worst \\
\cline { 2 - 3 } & Average & 77 \\
Mosul & 177 & 68 \\
Baghdad & 125 & 24 \\
Basrah & 84 & 24 \\
\hline
\end{tabular}

building for Mosul region.

The bearing pressure in Figure 5 is the average bearing capacity value. It is not distributed evenly and is subjected to concentric vertical loads. The colors in the figure give the indication of the amount of bearing pressure on soil. The yellow and red colors indicate that the pressure in this zone is in a critical state. These zones are very restricted and do not affect the soil beneath the foundation.

Figure 6 show the distribution of the bearing pressure under the foundation, when worst bearing capacity values were used at Mosul region. The red and yellow zones in the figure does not cover large portion that can 


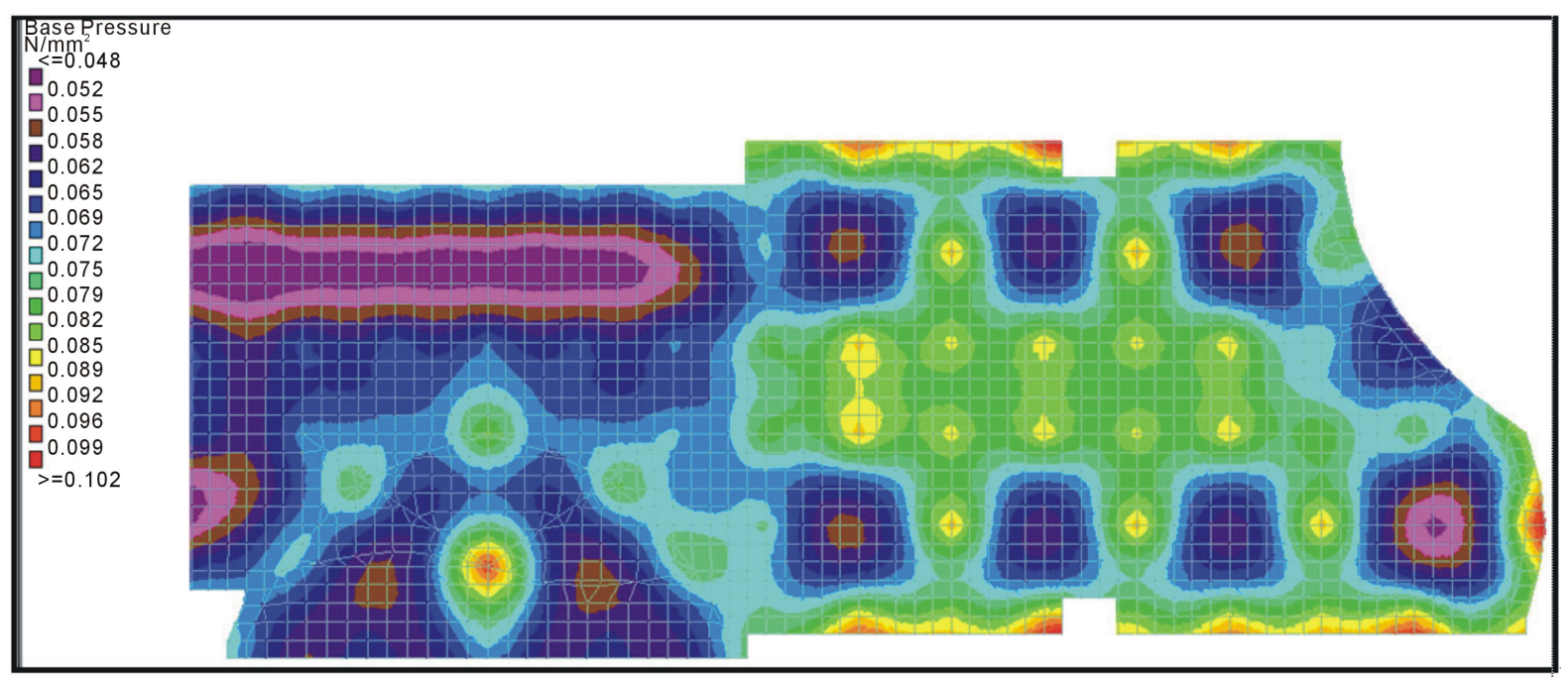

Figure 5. Base pressure distribution using the average value of bearing capacity at Mosul.

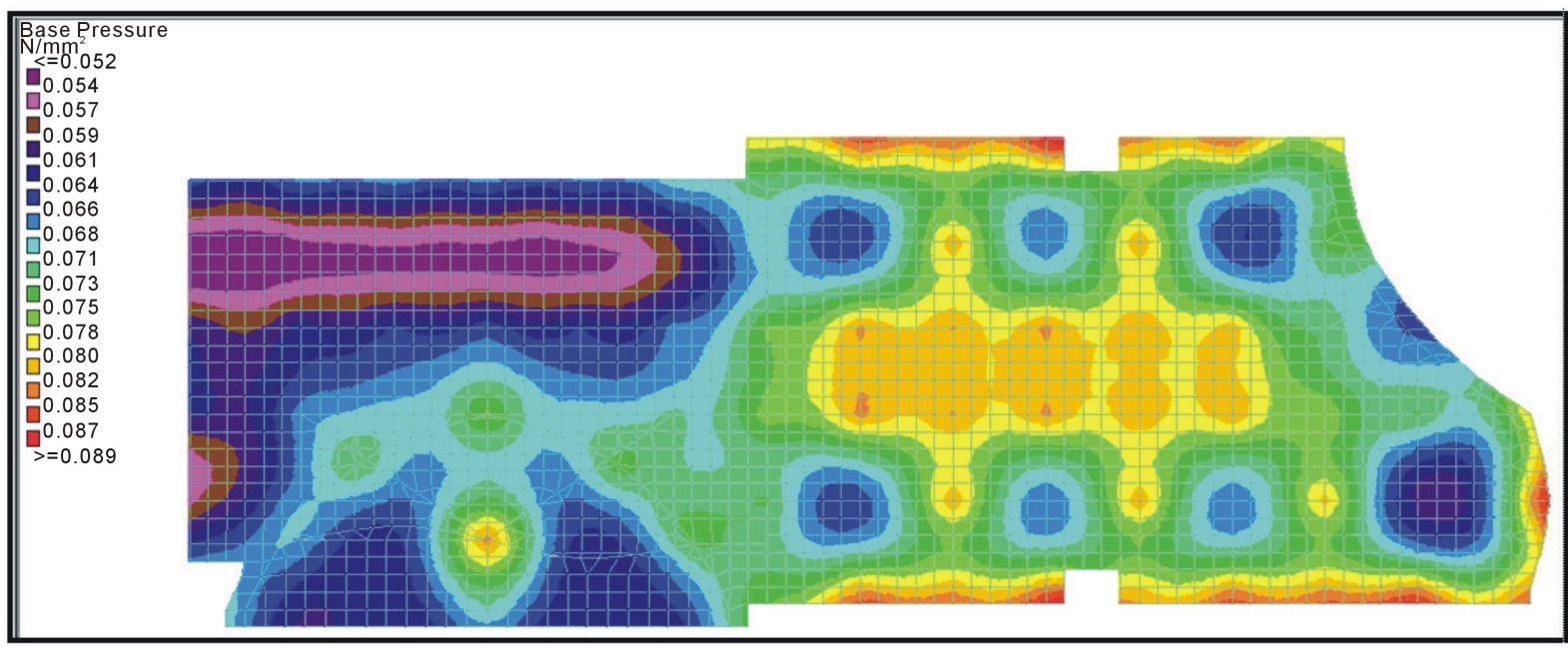

Figure 6. Base pressure distribution using the worst value of bearing capacity at Mosul.

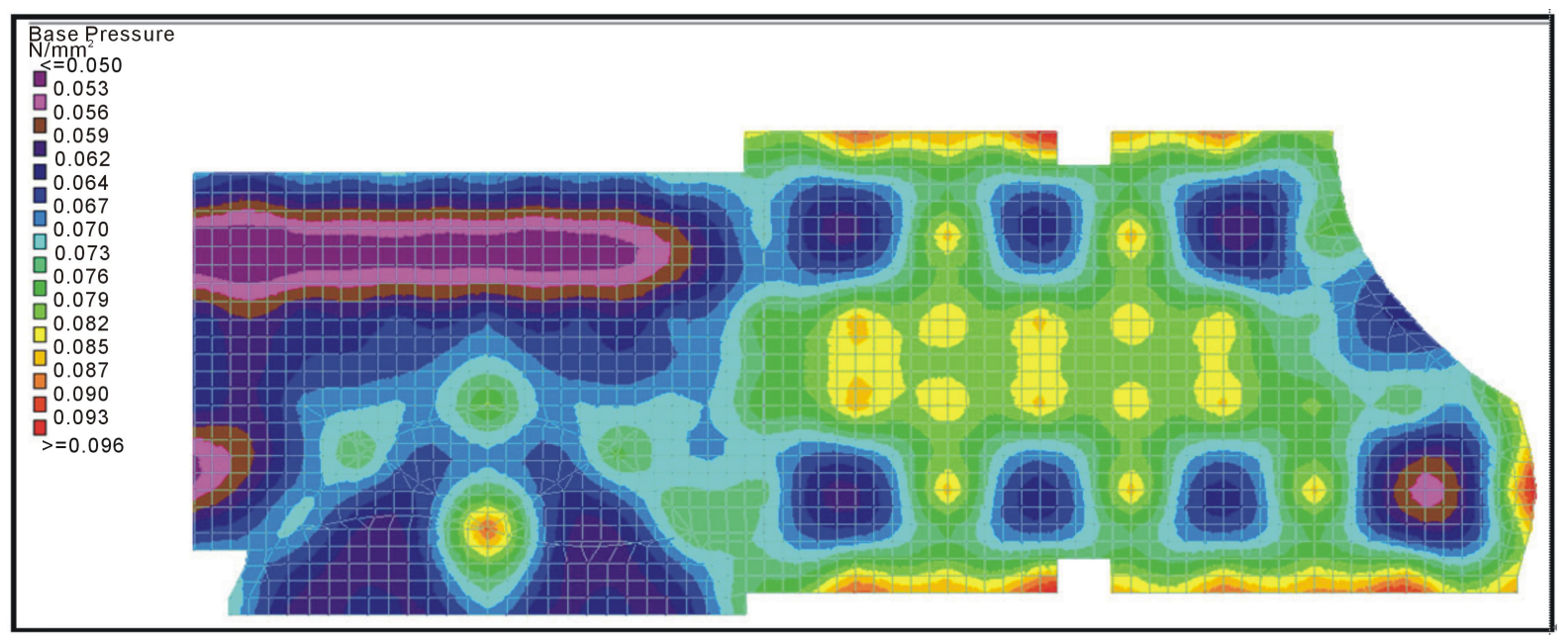

Figure 7. Base pressure distribution using average value of bearing capacity at Baghdad. 


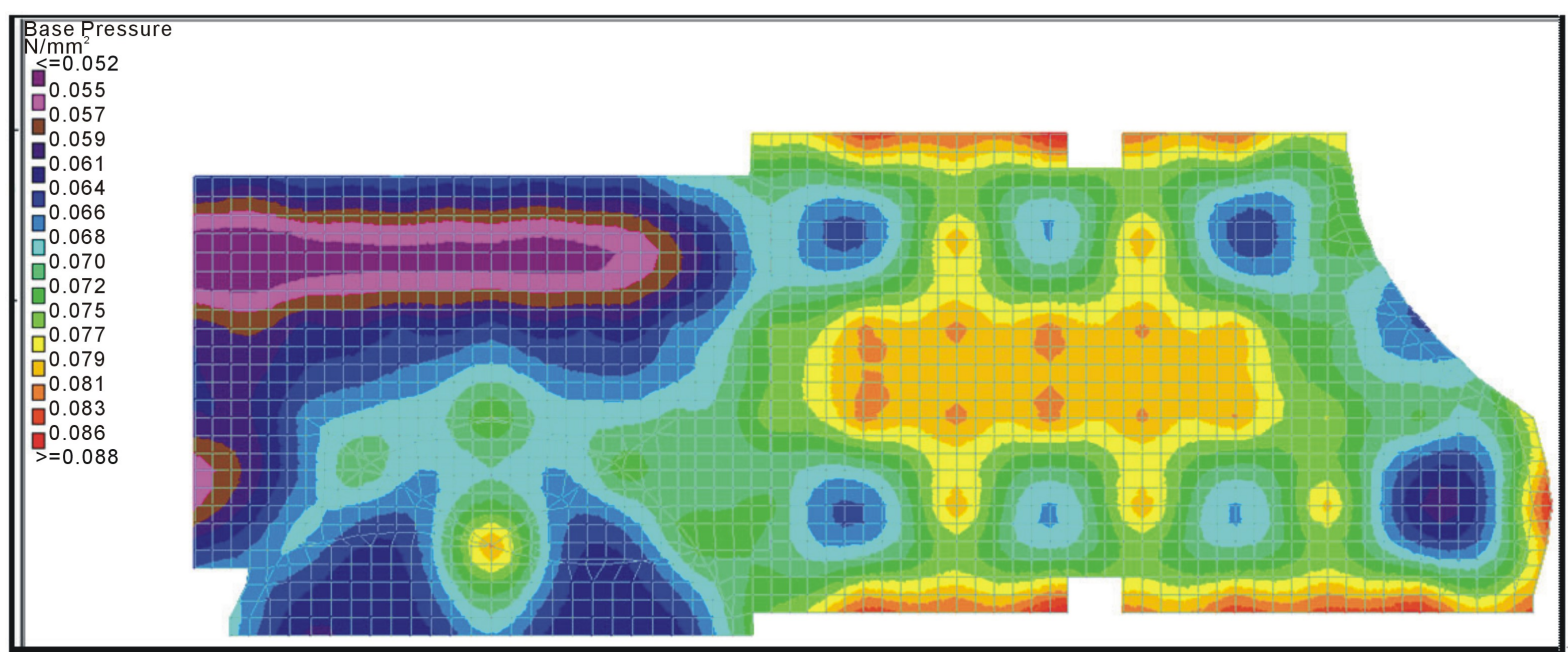

Figure 8. Base pressure distribution using the worst value of bearing capacity at Bagdad.

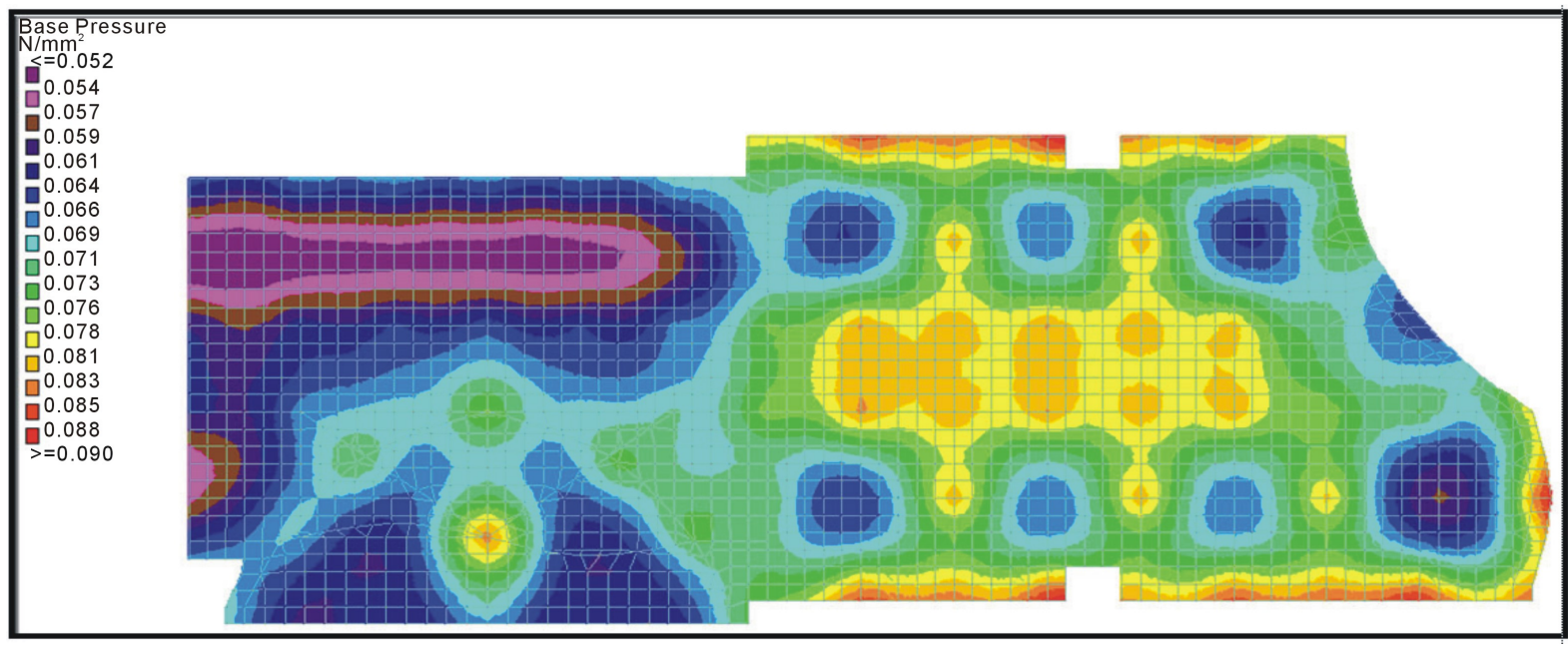

Figure 9. Base pressure distribution using the average value of bearing capacity at Basrah.

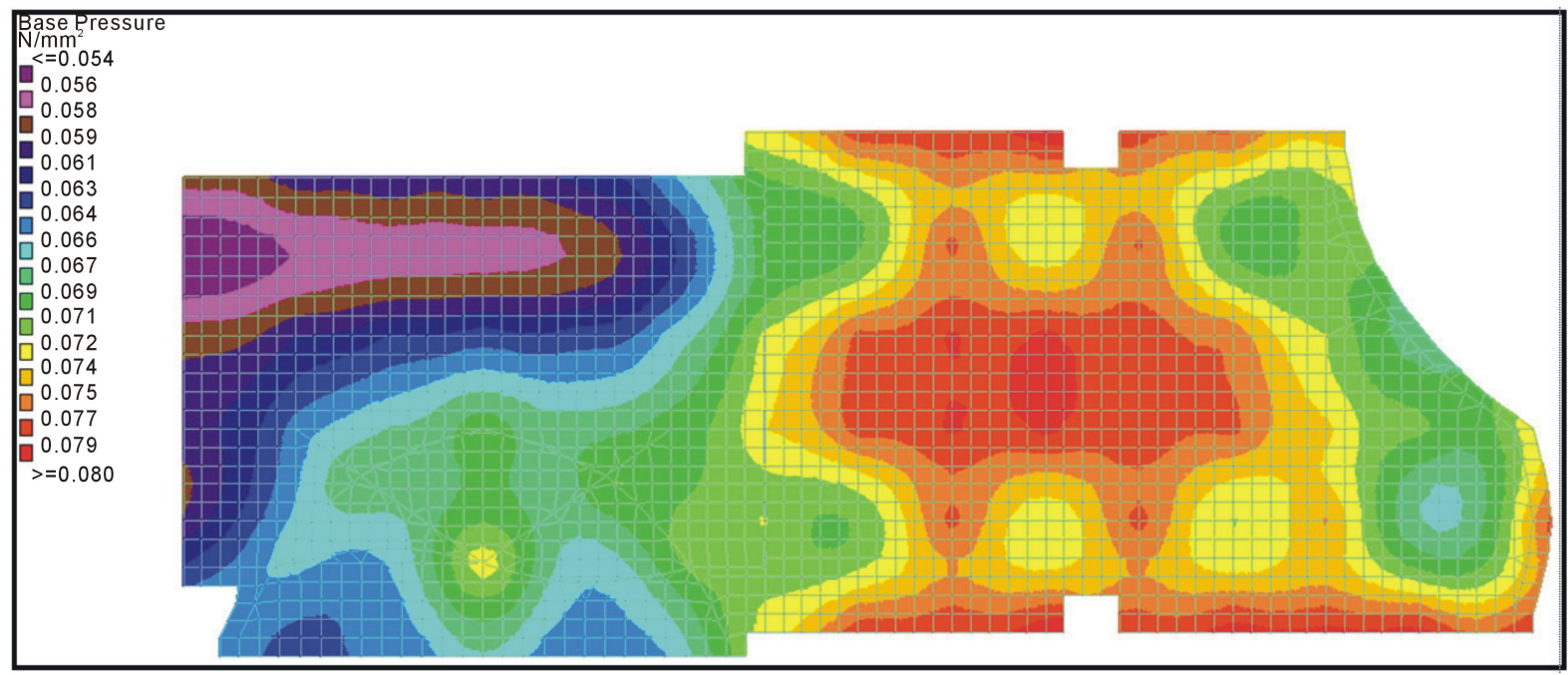

Figure 10. Base pressure distribution using the worst value of bearing capacity at Basrah. 
affect the soil under the foundation.

Figure 7 and Figure 8 show the effects of the bearing pressure on the soil that supports the foundation of the building at Baghdad region. As mentioned above, the bearing pressure under the foundation when using average bearing capacity values is not equally distributed (Figure 7). The yellow and red zones are covering small area that does not cause concern for the building.

Figure 8 show the distribution of the base pressure when using the worst bearing capacity values at Baghdad region. The red and yellow zones are large enough to affect the foundation but do not cause failure in the foundation. Therefore, we can consider the building is in safe mode.

The contours of Figure 9 show the distribution of the bearing pressure beneath the foundation when using the average value of bearing capacity at Basrah. The red and yellow zones appear in the figure are of moderate sizes, and they do not affect the soil beneath the building.

Figure 10 show the distribution of bearing pressure when the worst bearing capacity values are used at Basrah region. The figure includes many red and yellow zones. These zones are affecting soil under the foundation.

\section{Discussion}

The results obtained from the program showed that the bearing pressure under the foundation of the building model for Mosul region for the average value was $102 \mathrm{KPa}$; this value is less than the calculated value (177 $\mathrm{KPa}$ ). The worst value shown by the contour lines was $89 \mathrm{KPa}$. This value was restricted in small areas and had no effect on the foundation. Most of the areas under the foundation had a pressure value of $75 \mathrm{KPa}$. While, in the previous work done by Al-Taie, et al., (2013) [5] for the same building model using STAAD Pro Program and for one site in Mosul, the results showed that the value of the bearing pressure under the foundation was 73 $\mathrm{KPa}$, and in few areas was $115 \mathrm{KPa}$. These values had no effect on the foundation and it did not reach the calculated value (300 KPa). For this site, continuous or strip type foundation should be chosen. This will be more economical. As shown in Table 5.

In Baghdad region, the bearing pressure for the average value was unevenly distributed under the foundation (the range of value was 82 to $96 \mathrm{KPa}$ ), but it did not exceed the calculated bearing capacity (125 KPa).

The worst value of the bearing pressure under the foundation $(68 \mathrm{KPa})$, was equal to the value calculated. However, in some few areas under the foundation, the value of the bearing pressure was $88 \mathrm{KPa}$, which exceeded the calculated value and had no effect on the foundation. Previous work [5] of the bearing pressure under the foundation for one site in Baghdad showed two values. One was lower than the calculated bearing pressure (68 KPa) and occupied half of the area under foundation.

The other value of the bearing pressure was $77 \mathrm{KPa}$ which exceeded the calculated value $70 \mathrm{KPa}$. Therefore, the suitable choice of the foundation type for the area with the bearing capacity value less than the calculated value is strip or continuous foundation type. While for the area with high bearing capacity value, raft foundation is recommended.

For Basrah region, the result of the average bearing capacity value indicated that the bearing pressure was (78 $\mathrm{KPa})$ and did not reach the calculated value $(84 \mathrm{KPa})$. The result for the worst bearing capacity value showed that it exceeded the calculated value for whole the area under foundation. The calculated and the measured values of the bearing pressure were $24 \mathrm{KPa}$ and $72 \mathrm{KPa}$, respectively. Whereas, the previous work in Basrah for one site (Al-Taie, et al., 2013) showed that the bearing pressure under the foundation (71 KPa) was almost near the calculated value (50 KPa) of the bearing capacity. Therefore, raft foundation is recommended.

Table 5 shows the comparison between the current and previous work executed by Al-Taie et al. (2013). The value of the bearing capacity in the previous work for one site in each region of the three were higher than the worst value for the current work except for Mosul region. The average and worst values of bearing capacity are less than the previous work that was done by Al-Taie et al. (2013). Soil investigations specify the bearing capacity of the soil at a specific site so that suitable dimensions and type of foundation for the building can be considered. If the value of the bearing capacity is low, then the foundation dimensions should be large, and vice versa.

\section{Conclusions}

Seventy nine soil samples were collected from three different sites in Iraq (Mosul, Baghdad and Basrah) to investigate their effect on the foundation of the buildings. The results of the tests were used in a hypothetical 
Table 5. Comparison of the values of bearing capacity at three sites in Iraq from current and previous work [5].

\begin{tabular}{|c|c|c|c|c|c|}
\hline \multirow[b]{2}{*}{ Location } & \multicolumn{3}{|r|}{ Current work } & \multicolumn{2}{|c|}{ Previous work (Al-Taie et al., 2013) } \\
\hline & $\begin{array}{r}\text { Bearin } \\
\mathrm{A}\end{array}$ & $\begin{array}{l}\text { city KPa } \\
\text { rst }\end{array}$ & Suggestions & $\begin{array}{c}\text { Bearing } \\
\text { capacity KPa }\end{array}$ & Suggestions \\
\hline Mosul & 177 & 77 & $\begin{array}{l}\text { Use shallow foundation (continues, spread and mat is } \\
\text { to be used if the basement is required) }\end{array}$ & 300 & Any type of shallow foundation \\
\hline Baghdad & 125 & 68 & $\begin{array}{l}\text { Shallow foundation (spread and mat) is suitable } \\
\text { in use in some parts of Baghdad region for } \\
\text { buildings with not more than five floors }\end{array}$ & 70 & $\begin{array}{l}\text { Mixed } 2 \text { kinds of foundation } \\
\text { (raft and continuous) }\end{array}$ \\
\hline Basrah & 84 & 24 & $\begin{array}{l}\text { The mat foundation is the suitable type } \\
\text { for low buildings }\end{array}$ & 50 & Raft foundation \\
\hline
\end{tabular}

building and analyzed by STAAD Pro.v8i model. Soil in Mosul region includes many types such as clayey (expansive clayey), gypsum and silty clay. The results indicated that the bearing pressure under the foundation was lower than that calculated. Similar results were obtained when using the relatively worse bearing pressure values. Therefore, we can use shallow foundation (continues; spread and mat can be used if there was a basement) in Mosul area. These types of foundations can be used for buildings with many floors.

The soil in Baghdad region is of fluvial nature. The calculation of the bearing capacity gave high values in some parts of this region. These values seem to be normal since the soil layers in this region represent the accumulation of fluvial sediment. The results showed that the value of the average bearing pressure did not exceed the value calculated. This suggests that shallow foundation (spread and mat) is suitable to be used in some parts of Baghdad region for buildings with not more than five floors. When worse bearing pressure values were used, it was beyond the calculated bearing pressure which means that the mat foundation is suitable for these areas too.

In Basrah region the soil has irregular nature and consists of different strata as a result of the deposition of sediments by the Tigris and Euphrates Rivers. Basrah soil can be divided into three zones. The first zone depth values from $0.5-4 \mathrm{~m}$. It is hard silty clay soil. The second which is zone 5 - $19 \mathrm{~m}$ deep is cohesive soil, and the third zone 20 - $30 \mathrm{~m}$ deep is Cohesionless soil. The average bearing pressure was not exceeding the calculated value. Therefore, the mat foundation is the suitable type for low buildings (not more than three stores). When the worse bearing pressure values are used, it was evident that in most of the area under the foundation, it was higher than the calculated value. The suggestion for this area is deep foundation (piles). Therefore, shallow foundation is not the right choice.

The comparison of the results of this work and previous theoretical work for the same areas gave similar results.

\section{Acknowledgements}

All works of field and laboratory tests were done by the support of the Ministry of Higher Education and Scientific Research/Iraq. University of Mosul and Basrah, college of Engineering, Department of civil engineer greatly helped in sampling and laboratory testing. Especial thanks for Dr. Moataz Al-Obeydi and Dr. Qutayba Al-Saffar from University of Mosul for all their help and support. Great thanks for both engineers Abdul Hassan and Alaa from University of Basrah for all their support.

\section{References}

[1] Bowles, J.E. (1996) Foundation Analysis and Design. 5th Edition, McGraw-Hill Companies, Inc., Singapore.

[2] Coduto, D.P. (2001) Foundation Design: Principle and Practices. 2nd Edition, Prentice Hall, Upper Saddle River.

[3] Das, B.M. (2000) Fundamentals of Geotechnical Engineering. Brooks/Cole, Pacific Grove.

[4] Das, B.M. (2011) Principle of Geotechnical Engineering. 7th Edition, Cengage Learning, Stamford.

[5] Al-Taie, E., Al-Ansari, N, Knutsson, S. and Saad, T.E. (2013) Foundation Assessment in Different Parts of Iraq Using STAAD Pro v8i. Journal of Civil Engineering and Architecture, 7, 273-281.

[6] Buringh, P. (1960) Soils and Soil Condition in Iraq. Ministry of Agriculture, Baghdad.

[7] Jassim, S.Z. and Goff, J.J.C. (2006) The Geology of Iraq. Dolin, Hlvanf. 
[8] Sissakian, V.K. (2000) Geological Map of Iraq. 3rd Edition, State Company of Geological Survey and Mining, Baghdad.

[9] Al-Saoudi, N., Al-Khafaji, A. and Al-Mosawi, M. (2013) Challenging Problems of Gypseous Soils in Iraq. Proceedings of the 18th International Conference on Soil Mechanics and Geotechnical Engineering, Paris, 479-482.

[10] Khattab, S.A.A., Al-Juari, K.A.K. and Al-Kiki, I.M.A. (2008) Strength, Durability and Hydraulic Properties of Clayey Soil Stabilized with Lime and Industrial Waste Lime. Al-Rafidain Engineering, 16, 102-116.

[11] Khattab, S.A.A. and Al-Omary, A.M.A. (2009) Effect of Disturbance and Gypsum Content on Soil Water Characteristic Curve. 2nd International Conference on New Developments in Soil Mechanics and Geotechnical Engineering, Near East University, Nicosia, North Cyprus, 28-30 May 2009, 426-433.

[12] Al-Juari, K.A.K. (2009) Volume Change Measurement of Collapsible Soil Stabilized with Lime and Wasit Lime. Tikrit Journal of Engineering Sciences, 16, 38-54.

[13] Khattab, S.I.A., Abed, R.S. and Al-Imam, B.M.A.A. (2013) Analyzing Some Geotechnical Properties of Soils to Predict the Swelling Potential in the Left Side of Mosul City Using GIS Methods. International Journal of Chemical, Environmental \& Biological Sciences (IJCEBS), 1, 2320-4087.

[14] Karim, H.H., Ali, H.Z. and Hamdullah, A.H. (2010) Digitally Processed Geophysical Data Sets for Identification of Geological Features in Southern Iraq. Engineer \& Technology Journal, 28, 236-252.

[15] Mahmood, R. and Albadran, A.A. (2002) Geotechnical Classification and Distribution of the Quaternary Deposits in Basrah City, South of Iraq. Iraqi Journal of Earth Sciences, 1, 6-16.

[16] Kadhim, M.M., Al-Saoudi, N.K.S. and Ziboon, A.R.T. (2013) Digital Geotechnical Maps of Basrah City Using Geographical Information Systems Technique. Engineering \& Technology Journal, 31, 599-617.

[17] Al-Taie, M.A.J., Ali, A.M. and Albdran, B.N. (2009) Improvement of Selected Parts of Basrah Governorate Soil Using Resorcinol Resin. Basrah Journal of Sciences (C), 27, 1-16.

[18] Gunaratne, M. (2012) The Foundation Engineering Handbook. Taylor \& Francis Group, New York.

[19] Mohammed, A.H., Yahya, A.Y. and Ahmed, B.A. (2012) Database for Baghdad Soil Using GIS Techniques. Journal of Engineering, 18, 1307-1324.

[20] Subramani, T., Ponnuvel, D. and Deans, D. (2012) Seismic and Stability Analysis of Gravity Dams Using Staad PRO. International Journal of Engineering Research and Development, 1, 44-45.

[21] Bhattacharjee, B. and Nagender, A.S.V. (2007) Computer Aided Analysis and Design of Multi-Storeyed Buildings. BSc. Thesis, National Institute of Technology Roukela, Roukela.

[22] Bentley, (2011) Staad Pro \& Staad Foundation Software. http://www.staadpro.com

[23] ACI Committee 318-08 (2008) Building Code Requirements for Structural Concrete (ACI 318-08) and Commentary. American Concrete Institute, Farmington Hills. 